\title{
Arachis pintoi, PALATABILIDADE, CRESCIMENTO E VALOR NUTRICIONAL FRENTE AO PASTOREIO DE EQÜINOS ADULTOS
}

\author{
Arachis pintoi, the Palatability, Growth and Nutritional \\ Value to Grazing of Mature Equine
}

\author{
Cassiano Ricardo Weinhardt Baptista \\ Aluno formando do Curso Seqüencial Superior em Ciências Eqüinas da PUCPR. Curitiba - PR. \\ e-mail: crwbap@gmail.com \\ Cristiano Alves Moretini \\ Agrônomo, M. Sc., Prof. da PUCPR, São José dos Pinhais - PR. e-mail: camoretini@ibest.com
}

José Lino Martinez

Médico Veterinário, M. Sc., Quatro Barras - PR.e-mail: jlino@iapar.br

\section{Resumo}

A leguminosa Arachis pintoi é uma excelente fonte de forragem para cavalos e pode estar associada com a maioria das gramíneas, mesmo as mais agressivas. Ela tem aceitação muito boa e excelente valor nutritivo. Os bons resultados obtidos neste estudo, em relação à persistência na associação ou na cobertura de solo e na nutrição de cavalos, indica essa espécie como boa opção para o criador brasileiro de cavalos. Essa planta tem grande tolerância ao pastoreio, devido à sua estrutura de crescimento ser protegida da boca do animal, diferentemente da maioria das leguminosas tropicais.

Palavras-chave: Leguminosa; Arachis pintoi; Amendoim Forrageiro; Eqüinos.

\begin{abstract}
The leguminosae Arachis pintoi is an excellent source of horse forage and can be associated with the majority of the grasses, even the aggressive ones. It has a very good acceptability and an excellent nutritional value. The good results obtained in this study, regarding persistence in association or as ground cover and in the horse's nutrition, indicate this specie as a good option to the Brazilian horse breeder. This plant has great tolerance to grazing because its growing structures are protected from the mouth of the animal, differently than the most part of the tropical leguminosae.
\end{abstract}

Keywords: Leguminosae; Arachis pintoi; Pasture association; Equine. 


\section{INTRODUÇÃO}

O Arachis pintoi (Amendoim Forrageiro Perene) é uma leguminosa herbácea perene, de crescimento rasteiro, hábito estolonífero, prostrado e lança estolões horizontalmente em todas as direções em quantidade significativa, cujos pontos de crescimento são bem protegidos do pastejo realizado pelos animais. Adapta-se bem em solos de baixa a média fertilidade e tolera aqueles com alta saturação de alumínio (ácidos), porém, responde bem à calagem e adubação fosfatada. É uma leguminosa de porte baixo, dificilmente ultrapassando $30-40 \mathrm{~cm}$ de altura, possui raiz pivotante, que pode alcançar 1,60 m de profundidade. As hastes são ramificadas, circulares, ligeiramente achatadas, com entrenós curtos e estolões que podem chegar a 1,5 $\mathrm{m}$ de comprimento. A planta floresce várias vezes ao ano, geralmente entre a $4^{\mathrm{a}}$ e $5^{\mathrm{a}}$ semana após a emergência das plântulas. Em condições de sombreamento, as plantas apresentam crescimento mais vertical, com maior alongamento do caule, maior tamanho e menor densidade de folhas (CALEGARI et al., 1995; LIMA, 2007; SUPRAREAL, 2007).

Uma característica que confere grande tolerância ao pastejo é a localização de seus pontos de crescimento que, geralmente, encontram-se bem protegidos do alcance da boca do animal, ao contrário da maioria das espécies de leguminosas tropicais, que tem seus pontos de crescimento facilmente removidos em condições de pastejo intenso. Assim, é possível manter uma área foliar residual, mesmo quando a planta é submetida a um pastejo contínuo e intenso. Com relação ao frio, à seca, ao encharcamento e às cigarrinhas, essa leguminosa apresenta tolerância média segundo relatos de Calegari et al. (1995) e Lima (2007).

As pragas mais comuns que atacam essa leguminosa são os crisomélidos (que consomem as folhas), formigas e algumas larvas de lepidópteros. A presença dessas pragas ocorre de forma localizada dentro das pastagens e não afeta a persistência e a sua produtividade (CALEGARI et al., 1995; LIMA, 2007).

Apesar de terem sido identificadas diversas doenças que atacam o amendoim forrageiro, até o momento estas não têm limitado sua produção. De acordo com Lima (2007), o Arachis pode ser usado tanto na consorciação com gramíneas, como para recuperação de pastagens puras em processos de degradação. Sua densa rede de entolhos tem impacto positivo no controle da erosão (CALEGARI et al., 1995). Por ser ainda uma leguminosa perene, age como fixadora de nitrogênio, que promove boa cobertura de solo e controla plantas invasoras. Assim, foi objetivo da pesquisa proporcionar outra alternativa forrageira para melhorar a qualidade nutritiva da alimentação fornecida aos eqüinos criados na Região Metropolitana de Curitiba.

\section{MATERIAL E MÉTODOS}

O experimento foi conduzido no Instituto Agronômico do Paraná, com sede em Quatro Barras (PR), em meses de fevereiro de 2007. Foram utilizados três cavalos adultos (idade entre 08 e 12 anos), os quais foram colocados em um piquete com somente Arachis pintoi e outro piquete consorciado a Arachis pintoi com tifton 85 (FIGURAS 1 e 2). Após a colocação dos animais nos piquetes, procedeuse a observação comportamental do pastoreio dos animais. Os animais permaneceram primeiramente alimentando-se exclusivamente da leguminosa e posteriormente os animais foram colocados no piquete onde havia um consórcio de Arachis pintoi com tifton 85. Também se procedeu a análise bromatológica da leguminosa em laboratório (Laboratório da Pontifícia Universidade Católica do Paraná). 


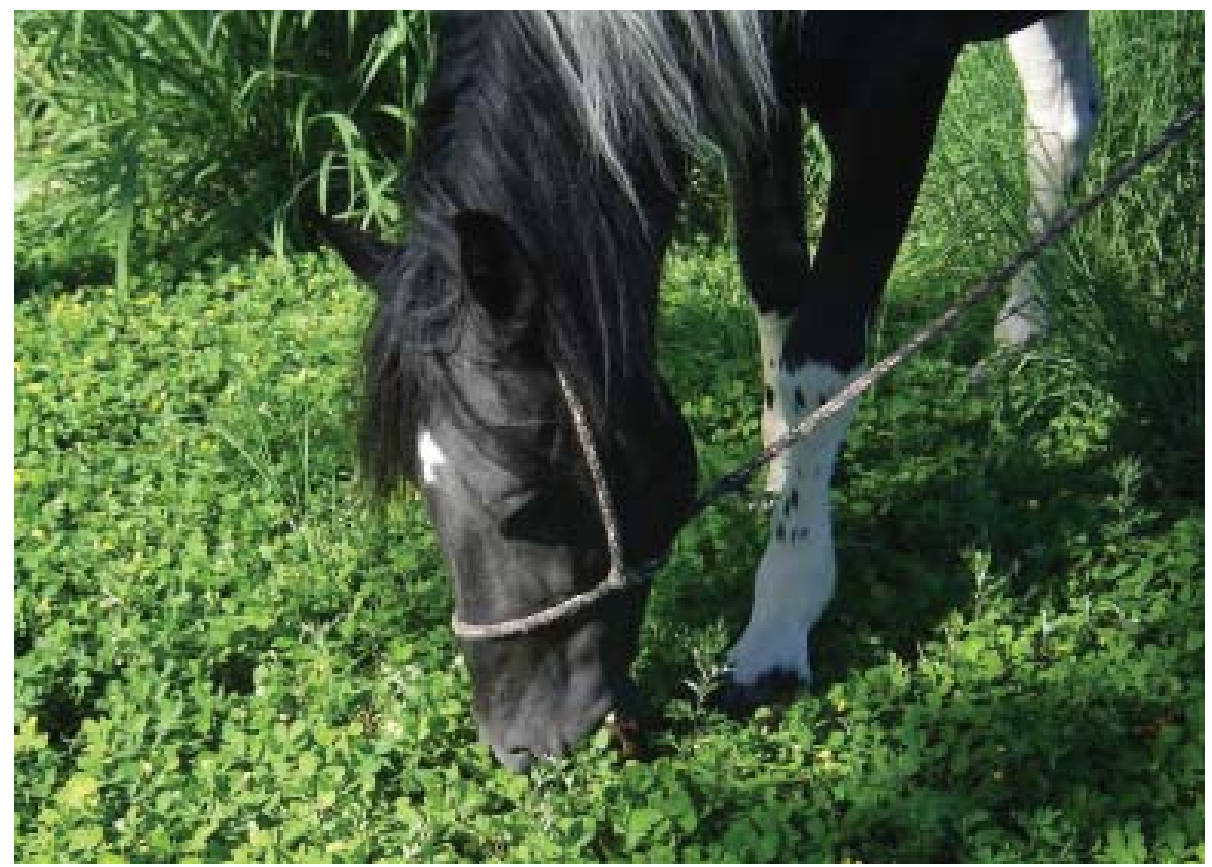

FIGURA 1 - Eqüino pastejando o piquete com Arachis pintoi sem consorciação em Quatro Barras - PR, 2007

Figure 1 - Equine grazing the Arachis pintoi leguminosae in Quatro Barras - PR, 2007

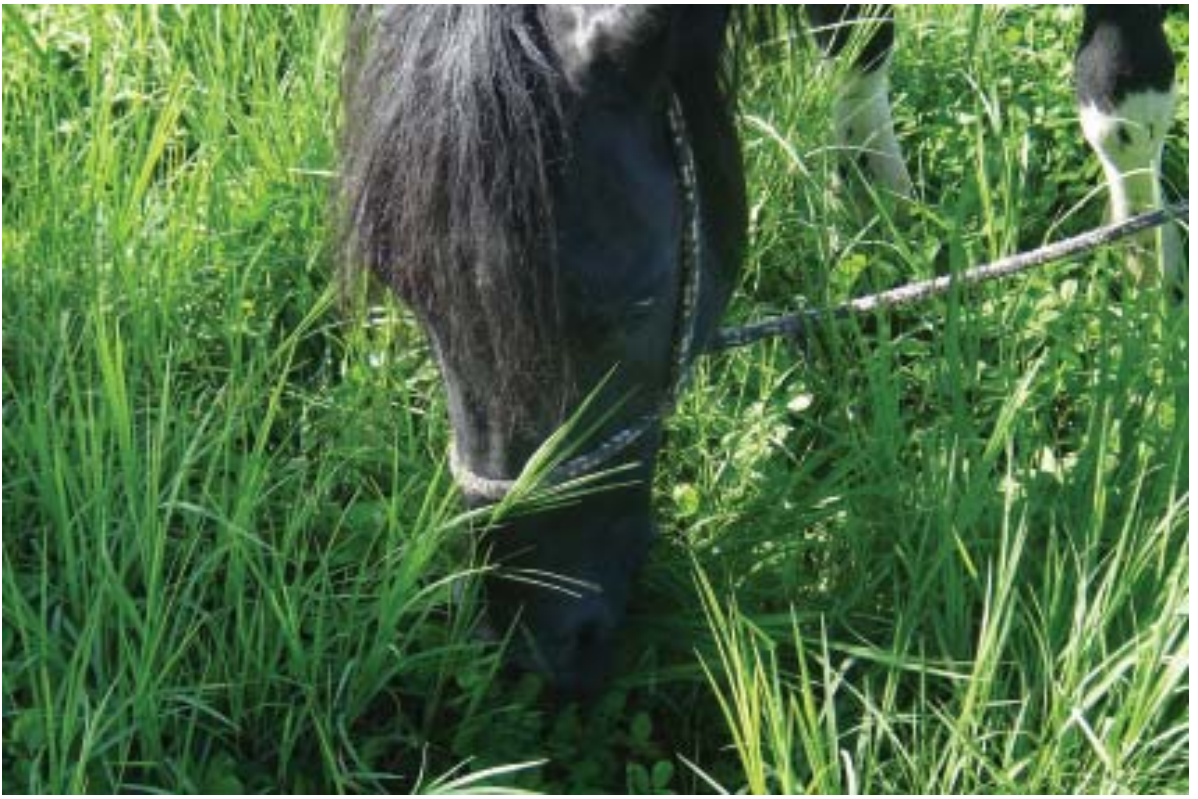

FIGURA 2 - Eqüino pastejando o piquete com Arachispintoi consorciado com o tifton 85 em Quatro Barras - PR, 2007

Figure 2 - Equine grazing the Arachis pintoi associated with Tifton 85 in Quatro Barras - PR, 2007 


\section{RESULTADOS}

Após a colocação dos animais em pastoreio, observou-se que esses executaram o pastejo de modo muito eficiente, não havendo rejeição ou escolha sobre qualquer parte do piquete, incluindo-se boa palatabilidade. Os animais pastejaram intensamente, tanto o Arachis pintoi, quanto a outra forrageira consorciada, sem demonstrar rejeição ou seletividade alguma. A seguir observa-se na Tabela 1 a análise bromatógica do Arachis pintoi.

TABELA 1 - Principais teores existentes no Arachis pintoi, após análise bromatológica, executada em Laboratório

Table 1 - Main components in the Arachis pintoi, after the bromatological analysis

\begin{tabular}{l|r}
\hline Composição Bromatológica & Percentagem \\
\hline Matéria seca (MS) & $92,92 \%$ \\
Residuo Mineral (RM) & $7,50 \%$ \\
Cálcio (Ca) & $1,09 \%$ \\
Fósforo (P) & $0,27 \%$ \\
Fibra Bruta (FB) & $23,40 \%$ \\
Extrato Etéreo (EE) & $2,42 \%$ \\
Proteína Bruta (PB) & $17,64 \%$ \\
Fibra em Detergente Neutro (FDN) & $51,60 \%$ \\
Fibra em Detergente Ácido (FDA) & $33,67 \%$ \\
\hline
\end{tabular}

RESULTADOS DA ANÁLISE BROMATOLÓGICA

Fonte: Laboratório da PUCPR

\section{DISCUSSÃO}

Com relação ao pastejo dos animais, observou-se nesse experimento que, ao contrário do que foi descrito por Lewis (1985), Pupo (1995) e Pilliner (1995), ao afirmarem que em pastos consorciados com os trevos (Trifolium spp) de diferentes espécies, os cavalos seletivamente pastejam as gramíneas e deixam as leguminosas, o pasto com Arachis pintoi foi ingerido imediatamente após a colocação dos animais no piquete, demonstrando excelente aceitação por eles. Nos piquetes da leguminosa sem consorciação houve boa aceitação e, ao se retirar os animais da área, verificaram-se insignificantes danos na pastagem devido ao pisoteamento, mantendo-se, contudo, os pontos de crescimento da planta preservados do alcance de corte dos animais, cujas estruturas vitais da planta remanesceram para futuro rebrote. Por sua vez, os animais, ao serem transferidos para os piquetes da leguminosa consorciada com tifton 85 , não impuseram seletividade sobre uma ou outra forrageira existente, pastando-as com semelhante intensidade.

Outra observação a ser salientada foi o fato de o Tifton 85 , apesar de constituir uma gramínea muito agressiva em termos de crescimento e perpetuação, não conseguir, nem parcialmente, suprimir o crescimento do Arachis pintoi, que se desenvolveu muito bem na consorciação, corroborando relatos de Lima et al. (2007).

Dados relativos ao valor nutricional do Arachispintoi dão conta de que a leguminosa contempla muito bem as necessidades diárias dos eqüinos, quando se confrontam os relatos de Lewis (2000), ao estudar diversas outras leguminosas.

A composição bromatologica do Arachis pointoi cultivada em Quatro Barras (PR) foi muito semelhante àquela relatada por Valadares Filho, Rocha Júnior e Capelle (2001), ao analisar a planta em Minas Gerais. 


\section{CONCLUSÕES}

Concluiu-se que Arachispintoi, empregado isoladamente ou consorciado, teve grande aceitação pelos animais (boa palatabilidade), além de significativamente suprir as necessidades diárias, em função dos dados da análise bromatológica efetuada.

\section{REFERÊNCIAS}

CALEGARI, A. et al. Leguminosas para adubação verde de verão no Paraná. Londrina: Sociedade Brasileira de Zootecnia, 1995.

LEWIS, L. D. Nutrição clínica eqüina: alimentação e cuidados. São Paulo: Roca, 2000. 689 p.

. Alimentação e cuidados do cavalo. São Paulo: Roca, 1985. 248 p.

LIMA, J. A. et al. Amendoim forrageiro (Arachis pintoi Krapov. \& Gregory). 2003. UFLA/ CNPq. Disponível em: < http://www.editora.ufla.br/Boletim/pdfextensao/bol_01.pdf>. Acesso em: 07 jun. 2007.

PILLINER, S. Nutrición y alimentación del caballo. Zaragoza: Acribia, 1995. 207 p.

PUPO, N. I. H. Manual de pastagens e forrageiras. Campinas: Instituto Campineiro de Ensino Agrícola, 1995.

SUPRAREAL. Sementes de inverno: Arachis Pintoi. 2007. Disponível em: <http:// www.suprareal.com.br/inverno.php?Arquivo=51>. Acesso em: 26 fev. 2007.

VALADARES FILHO, S. C.; ROCHA JR., V. R.; CAPELLE, E. R. Tabelas brasileiras de composição de alimentos para bovinos. Viçosa: UFV, DZO, DPI, 2001. p. 58-61.

Recebido em: 25/04/2007

Received in: 04/25/2007

Aprovado em: 31/07/2007

Approved in: 07/31/2007 